\title{
Improving Technological Services and Its Effect on the Police's Performance
}

\author{
Nazanin Mansouri \\ HELP University \\ Kuala Lumpur, Malaysia
}

\begin{abstract}
The role of police department in any country is critical. It is obvious that improving the technology in police department can be done with safety and contributes to improve its economy. This paper, first tries to recognize the existed weaknesses in used technologies. Then, it will suggest the best approach. The proposed framework of this study points out to two different moderating roles that can be considered as technical contributions. Moreover, the combination of this proposed framework is new for current study. This framework is concentrated on technology improvement, knowledge management system, technology acceptance, police performance, and ministry performance.
\end{abstract}

Keywords: technology improvement, knowledge management system, technology acceptance, police performance, and ministry performance.

\section{INTRODUCTION}

The emerging and new technologies have a remarkable key role in every day work of the police and it equips the officers with investigative and enforcement devices that are able to provide them safety, information as well as higher efficiency and effectiveness.

Enforcing and developing comprehensive policies of agency about the use and deployment is a major step for understanding the value promised by technologies and is necessary for making sure the public that their civilized liberties and privacy are all protected and understood.

The advancements in technology provided the possibility for recording and monitoring each of the interactions among public and police by means of body worn and in car video, accessing to expanded network of private and public video systems, as well as enhancement in use of those smart phones which have recording abilities by officers and the citizens. In this case police will be able to track the suspect by means of GPS technologies for tracking and the officers also can be tracked by (AVL) automated vehicle location systems.

The system of (ALPR), automated license plate recognition can be considered as the plates of license for vehicles insight of officers while they are in field and it will alert them very fast when the vehicle was reported as being wanted or stolen. The identity can be established or verified remotely through biometric precisions by means of mobile scanners of fingerprint or software for facial recognition. They can map the crime when they are being reported, the technology of gunshot detection is able to alert the enforcement of law quickly at the time that firearm is being discharged and the cameras have the capability to be programmed for concentrating on location of gunshot and provide live videos for both officers and dispatchers.

According to the mentioned points above, it can be concluded that using new technologies is necessary in order to improve police performance. However, the important point is the fact that if the employees of this organization are interested to use this technology or not? In addition, another question is that how the new technologies can be used in higher organizational levels.

For answering the first question we can refer to the conducted studies by some researchers such as Delone and Mclean
(2004). These researches mainly emphasized on factors such as quality, technology acceptance and etc.

In order to answer the second question, we can refer to the value of knowledge management system (KMS). Previous studies (e.g. Yang et al., 2012) demonstrated that KM can affect the project performance. Hence, studying the role of KM system in macro dimensions have been discussed less. On the other hand, using e-government these days facilitated the relationship between government organizations. However, the existed knowledge and experience in police department can be used to positively improve e-government performance.

Because of the fact that every country uses new technologies in its e-government so police departments also need new and modern technologies to be engaged with. It is clear that police department should evaluate and improve itself. On the other hand the employee behavior regarding usage of new technologies is one of the common issues in organizations. The experiences of polices in case of using new technologies and its weakness and strength points should be considered for making macro decisions and this can highlight the role of $\mathrm{KM}$. according to the complexity and ambiguity for improving the performance of Ministry of Internal Affair, this research attempts to study the relationship among technology acceptance of employees, technology improvement, Ministry and $\mathrm{KM}$ performance and also department performance.

\section{LITERATURE REVIEW 2.1. Theory of Acceptance Model}

There are many various research related to different models of consumer acceptance. Among them some are relevant to a specific model or theory and the rest try to make comparison between models and join them in order to get better results. The model of technology acceptance (TAM) is one of the famous models in case of customer acceptance which was presented by Davis (1989). All of the customers generally may use high tech products and services for not only taking advantage but instead for having the experiment with their usage (Kulviwat, Bruner, Kumar, Nasco, and Clark, 2007). The primary goal of TAM would be providing a definition for different dimensions of adoption which are all general for being employed in many innovative technology activities (Davis, Bagozzi, and Warshaw, 1989). 
This model focuses on two main considerations as easy to be used and usefulness. The assumed benefit is the degree to which a potential customer might think by using a specific device or tool which can improve their total performance and also the easy to be used assumption is the fact that to think using a specific technology will not require high work and energy levels.

\section{Technology Acceptance Model (TAM)}

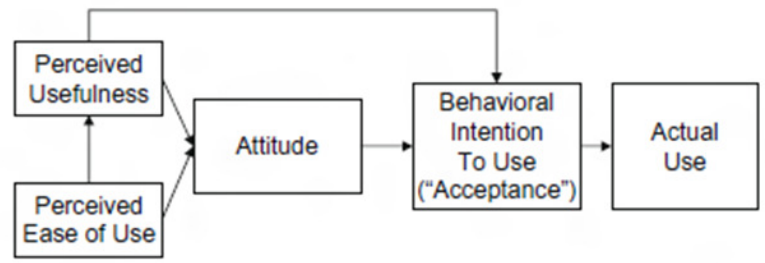

Figure 1: TAM by Davis (1989)

In researches about the field of societal sciences, the existed causality analyses the relationships significantly influences the efficiency of decision making. Previous investigations which studied the (TAM) or technology acceptance model and also (UTAUT) known as use and acceptance technology theory in general employ structural equation modeling (SEM).

\section{Unified Theory of Acceptance and Use of Technology (UTAUT)}

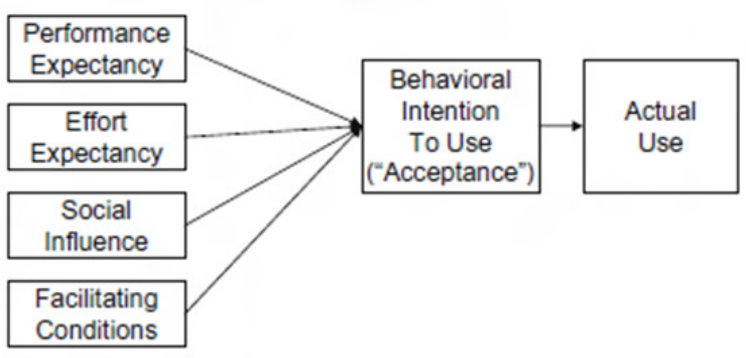

Figure 2: UTAUT

The collected statistical data however, allows the analysts to modify the mentioned model in order to prepare an appropriate model of fitness and basically SEM is misused when the data is fit rarely for structural equation modeling. Conceptual model or theory can be expanded through analytical results based on the developed hypotheses $(\mathrm{Wu}$, Huang, Tzeng and Wei, 2010).

\subsection{IS Success Model}

The IS or information system concept is a remarkably accepted tool for assessing the IS (Lin, 2006). In case of MIS for managing the IS scholarships, a lot of experts suggested different IS success models (Seddon and Kiew, 1994, Mclean and Delone, 1992, 2003, 1997; Pitt et al., 1995). These models bring many definitions or factors for IS success systems that influence the noted IS success. The models are theoretically generated and empirically examined. Thus, many scholars did investigations about success factors of these models that are being employed for evaluating the IS successes as well as performance. After reviewing above 180 articles in field of IT investment evaluation factors that were published in 1970s and 1980s, then Mclean and DeLone (1992) proposed a model for IS success which had six main variables related to IS success, information quality, system use, system quality, user satisfaction and finally organizational and personal impacts. This model presented coherent and dependent factors used by the IS experts, it achieved a lot of critiscm. Firstly, employing the information system in provided model by DeLone and McLean can have different interpretations for being analyzed appropriately. In addition using the information system has a problematic and controversial role for IS success model. Then, because of the fact that satisfaction has individual impacts of information system within the organizational context, looking for cause path from user satisfaction to individual impacts is not useful. Finally, this model cannot fully explain the relationship between impacts of user satisfaction and individual / organizational (Edward, 2005). This definition for this construct is as follows:

1. System quality: evaluating the information processing system on its own

2. Information quality: evaluating the IS output

3. Using information: IS consumption and output of receiver

4. Satisfaction of users: reaction of receiver for utilizing the output from IS

5. Personal influence: Influence from information relevant to behavior of recipient

6. Organizational influence: Impact of information for firm's performance

S-K. Lee, J-H. Yu / Automation in Construction 25 (2012) 82-93

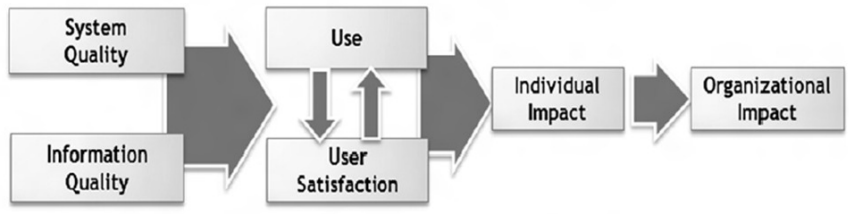

Figure3: IS success mode by Mclean and Delone (1992)

In 1994, Seddon \& Kiew reviewed an altered version of developed model by DeLone and McLean (1992) which had three below primary differences:

(a) For being useful the use was modified, (b) one new factor, systems importance also were noted for defining different user assumptions which are related to satisfaction as well as usefulness of the users and at last (c) stimulation causality among user satisfaction and use has been replaced with casual single way for instance being useful always results to upstream for two third from developed model of Mclean (1992). Moreover, Seddon in 1997, introduced an IS success model which demonstrates that society impact is considered as the net IS advantage (Fig.2.7).

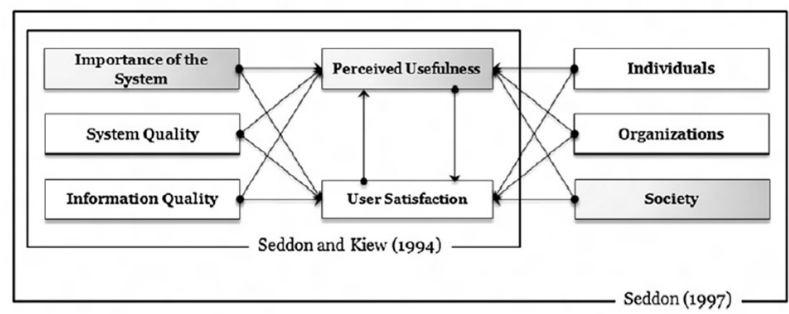

Figure 4: IS success model by Seddon and Kiew (1994)

The IS success model developed by Pitt et al. (1995) revealed the fact that service quality is another quality factor for developed model by Mclean and DeLone (1992). All of the measurement items for evaluating the service quality are 
SERVQUAL which is altered and suggested by A Parasuraman et al. (1998); so the other validity was tested (Fig.5).

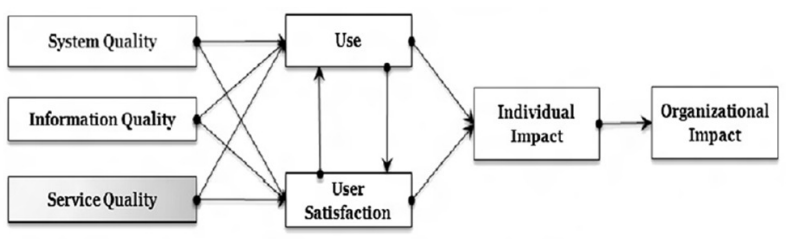

Figure 5: IS success model by Kawan et al. (1995)

\subsection{Knowledge Management System}

In a not certain economy, a company can reach CA by means of knowledge (Nonaka et al., 2009). In this regard, a company for reaching success increases the internal knowledge of the organization (Nonaka et al., 2009).

Based on statements of Brian Newman (1995) the collection process which results in creation, knowledge utilization as well as dissemination is known as (KM) or knowledge management. Knowledge management has been recognized and realized for many decades ago. These days different scholars know the usage of knowledge for example philosophers, scribes, teachers and also priests (Newman et al., 1995).

Here the question is that if $\mathrm{KM}$ has been used for decades so what is the role of KM relevant to information nowadays? The mentioned progresses are existed and they have a remarkable impact on decision making as well as action taking. They both probably are made with different types of knowledge. Based on Thomas Bertels statements, renewal system knowledge management of organizations is called as knowledge management or KM for example (Savage \&Bertels, 1999)

I. Developing supportive structure for the firm

II. Putting IT-Tools

III. Facilitation the organization employees

The practical person, Thomas Bertels, highly focused on practical aspects of knowledge for real improvements. The conducted researches by Yang et al. (2012) and Tsai (2001) demonstrated that knowledge management has the capability to impact performance.

\section{CONCLUSION AND FUTURE STUDY}

The role of police department in any country is critical. It is obvious that improving the technology in police department can be done with safety and contributes to improve its economy. This study, first tries to recognize the existed weaknesses in used technologies. Then, it will suggest the best approach. The proposed framework of this study (See Figure 6) points out to two different moderating roles that can be considered as technical contributions.

According to the mentioned points above, technology acceptance models show that which factors might impact "use". In addition, IS success model based on some factors such as quality attempts to extend the impact of "use" and "user satisfaction" on individual performance and organizational performance.

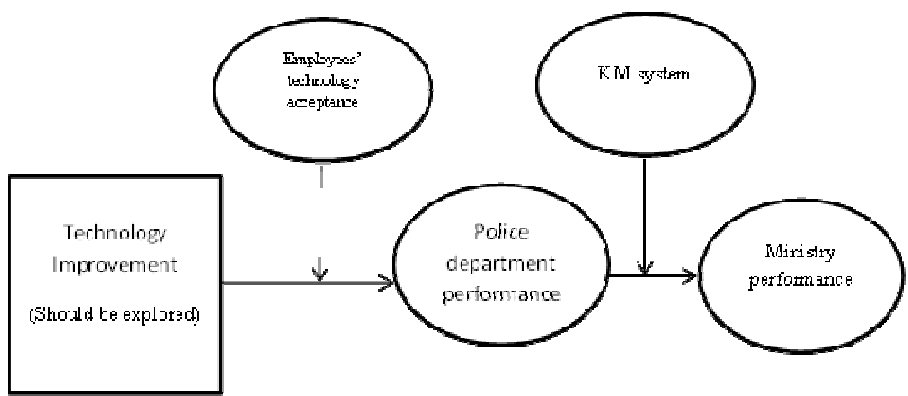

Figure 6: Proposed Framework

On the other hand, KM has been recognized as one of the important factors in previous studies which have the potential to impact performance and also macro decision makings. It should be mentioned that the relationships in this framework all have been supported by previous studies.

Firstly, future study can apply the qualitative approach. This approach helps to explore the weaknesses in the current technology which is being applied. Secondly, several hypotheses should be developed based on the proposed framework. To test the hypotheses, the quantitative approach is efficient.

\section{REFERENCES}

[1] A. Parasuraman, V.A. Zeithaml, L.L. Berry, SERVQUAL: A multiple-item scale for measuring consumer perceptions of service quality, Journal of Retailing 64 (1) (1998) 12-40.

[2] Bertels, T., \& Savage, C. M. (1999). A research agenda for the knowledge era: the tough questions. Knowledge and Process Management, 6(4), 205.

[3] Davis, F. D., Bagozzi, R. P., \& Warshaw, P. R. (1989). User acceptance of computer technology: a comparison of two theoretical models. Management science, 35(8), 982-1003.

[4] Davis, F.D. Perceived usefulness, perceived ease of use, and user acceptance. MIS Quarterly 75, 3(1989), 319341.

[5] Kulviwat, S., Bruner, I. I., Gordon, C., Kumar, A., Nasco, S. A., \& Clark, T. (2007). Toward a unified theory of consumer acceptance technology. Psychology \& Marketing, 24(12), 1059-1084.

[6] L.F. Pitt, R.T. Watson, C.B. Kavan, Service Quality: A Measure of Information System Effectiveness, MIS Quarterly 19 (2) (1995) 173-187.

[7] Nonaka, I., \& Von Krogh, G. (2009). Perspective-tacit knowledge and knowledge conversion: Controversy and advancement in organizational knowledge creation theory. Organization science, 20(3), 635-652.

[8] P.B. Seddon, A Respecification and Extention of the DeLone\& McLean's Model of IS Success, Information System Research 8 (3) (1997) 240-253.

[9] P.B. Seddon, M.Y. Kiew, A Partial test and development of DeLone and McLean's Model of IS Success, Proceedings of the International Conference on Information Systems 4 (1) (1994) 90-110.

[10] S.C. Lin, S.S. Tseng, W.G. Tzeng, S.M. Yuan, A Framework of High-Confidence e- Healthcare 
International Journal of Science and Engineering Applications

Volume 4 Issue 5,2015, ISSN 2319-7560 (Online)

Information System, Asian Journal of Health and Information Sciences 1 (2) (2006) 176-188.

[11] Seddon, P. A respecification and extension of the DeLone and McLean model of IS success. Information Systems Research, 8, 3 (1997), 240-253.

[12] Tsai, W. (2001). Knowledge transfer in intraorganizational networks: Effects of network position and absorptive capacity on business unit innovation and performance. Academy of management journal, 44(5), 996-1004.

[13] Wang, R.Y., and Strong, D.M. Beyond accuracy: What data quality means to data consumers. Journal of
Management Information Systems, 12, 4 (Spring 1996), 5-34.

[14] W.N.B. Edward, IT governance for enterprise resource planning supported by the DeLone\&McLean model of information systems success, Information Management 45 (5) (2008) 257-269.

[15] W.H. DeLone, E.R. McLean, Information system success: The Quest for the Dependent Variable, Information Systems Research 3 (1) (1992) 60-95.

[16] W.H. DeLone, E.R. McLean, TheDelon and McLean Model of Information System Success: A Ten-Year Update, Journal of Management Information Systems 19 (4) (2003) 9-21. 